2. To: (Receiving Organization)

Distribution

5. Proj./Prog./Dept./Div.:

8P400/MD4CT

8. Originator Remarks:

This document is an implementation guide for fiber optic loop sensors used as detection elements in security monitoring applications.

11. Receiver Remarks:
3. From: (Originating Organization)

6. Cog. Engr.:

R. G. Swank WHC Technical Security

4. Related EDT No.:

n.a.

7. Purchase Order No.:

n.a.

9. Equip./Component No.:

n.a.

10. System/Blog./Facility:

n.a.

12. Major Assm. Dwg. No.:

n.a.

13. Permit/Permit Application No.: n.a.

14. Required Response Date: $05 / 29 / 96$

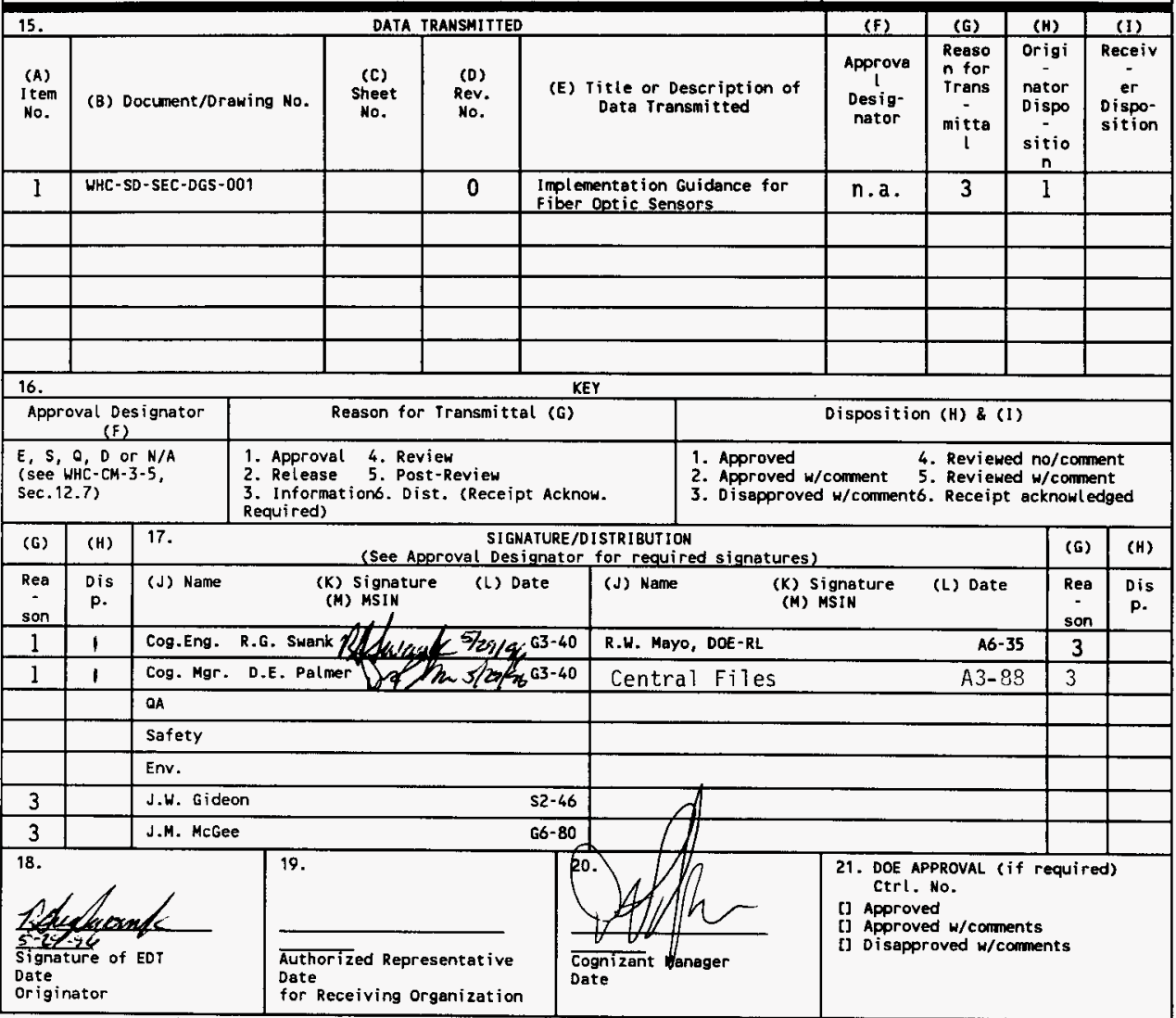




\section{Implementation Guidance for Fiber Optic Loop Sensors}

R. G. Swank

Westinghouse Hanford Company, Richland, WA 99352

U.S. Department of Energy Contract DE-ACO6-87RL10930

$\begin{array}{lll}\text { EDT/ECN: } & 615743 / \text { n.a. } & \text { UC: } 900 \\ \text { Org Code: } 8 P 400 & \text { Charge Code: } \\ \text { BRR Code: } & \text { YN0100000 } & \text { Total Pages: } 25\end{array}$

Key Words: fiber optic loop sensor, optical sensor, implementation guide, active seal

Abstract: Fiber optic loop sensors are a form of active security seal that can be used for detecting attempts to move or. access secured items. This document is a guide that provides information about this type of sensor and suggests possible implementations.

TRADEMARK DISCLAIMER. Reference herein to any specific comercial product, process, or service by trade name, trademark, manufacturer, or otherwise, does not necessarily constitute or imply its endorsement, recommendation, or favoring by the United States Government or any agency thereof or its contractors or subcontractors.

Printed in the United States of Anerica. To obtain copies of this document, contact: WHC/BCS Document Control Services, P.O. Box 1970, Mailstop H6-08, Richland WA 99352, Phone (509) 372-2420; Fax (509) 376-4989.
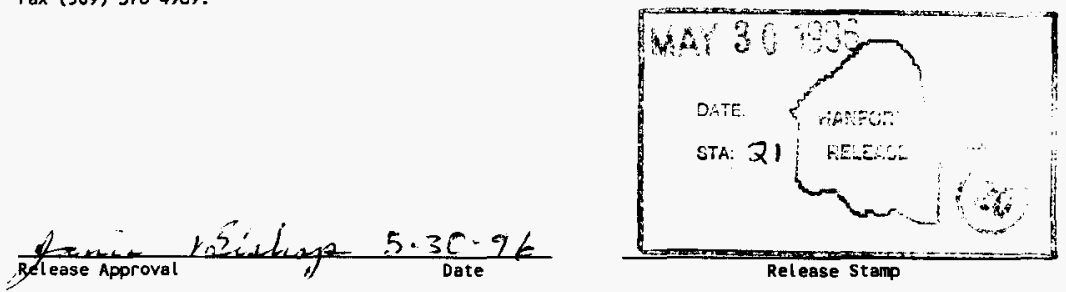

\section{Approved for Public Release}


WHC-SD-SEC-DGS-001, Rev. 0

\title{
IMPLEMENTATION GUIDANCE FOR FIBER OPTIC LOOP SENSORS
}

\author{
prepared by \\ Westinghouse Hanford Company \\ Technical Security
}

May 31, 1996 
WHC-SD-SEC-DGS-001, Rev. 0

May 31, 1996

\section{Abstract}

Fiber optic loop sensors are a form of "active" security seal that can be used for detecting attempts to move or access secured items. The sensor uses a fiber optic cable loop with light passing through it as the detection element and causes an al arm condition when the loop continuity is interrupted by breaking the cable or detaching it from the sensor housing. This guide provides information about this type of sensor and suggests possible implementations. 
Implementation Guidance for Fiber Optic Loop Sensors

$$
\text { table of contents }
$$

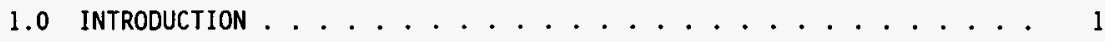

2.0 PURPOSE $\ldots \ldots \ldots \ldots \ldots \ldots$

3.0 SCOPE $\ldots \ldots \ldots \ldots \ldots \ldots \ldots$

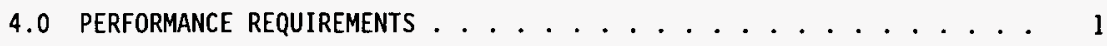

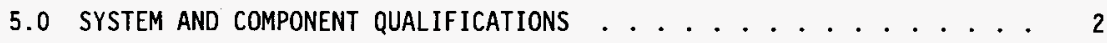

6.0 COMPONENT DESCRIPTION . . . . . . . . . . . . . . . 2

6.1 VSS $100 \ldots \ldots \ldots 2$

6.2 vSS $200 \ldots \ldots \ldots 3_{3} \ldots \ldots \ldots \ldots \ldots \ldots \ldots . \ldots \ldots$

6.3 VSS $300 \mathrm{~B} \ldots \ldots \ldots \ldots$

6.4 VSS 500RF . . . . . . . . . . . . . 3

6.5 VSS 3500 NCB . . . . . . . . . . . . . . . . . . . . . 4

6.6 VSS 3600 NCB . . . . . . . . . . . . . . . . . . . 4

6.7 VSS 5504RFP, VSS 5508RFP, VSS 5516RFP . . . . . . 4

6.8 VSS $4100 \mathrm{P}$, vSS $4200 \mathrm{P} \ldots \ldots \ldots . \ldots \ldots$

6.9 VSS $4710 \mathrm{CS}$, vSS $4720 \mathrm{CS} \ldots \ldots . \ldots . \ldots . \ldots . . \ldots 4$

7.0 PERFORMANCE EXPECTATIONS .................. 4

8.1 SYSTEM PLANNING . . . . . . . . . . . . . . . . . . 6

8.2 DESIGN AND OPERATIONAL ISSUES . . . . . . . .

References:.................. . . 9

Appendix A: APPLICATIONS

Appendix B: FIGURES 
WHC-SD-SEC-DGS-001, Design Guide

May 31, 1996

Revision 0

Implementation Guidance for Fiber Optic Loop Sensors

page 1 of 9

\subsection{INTRODUCTION}

Fiber optic loop sensors (FOLS) are a form of "active" security seal that can be used for detecting attempts to move or access secured items. FOLSs usually consists of a small module housing an optical transmitter and receiver with a length of fiber optic (F0) cable running between the transmitter and receiver terminals. Pulses of light are injected into the Fo cable at the transmitter and detected at the receiver terminal. If the FO loop is broken an alarm condition is signaled through the actuation of a dry contact, low going transistor, or coded signal, depending on the manufacturer and model, which can be tied into a monitoring system or used to activate local alarms. Properly installed and operating FOLS have demonstrated an extremely low false alarm rate and a high probability of detection.

\subsection{PURPOSE}

This document is a guide. Its purpose is to provide information about FOLS and suggest implementation strategies for commercially available off-theshelf devices.

\subsection{SCOPE}

This guide includes operating characteristics, component and system design considerations, and installation techniques and options for optical loop security sensors. The application and installation techniques described herein provide basic system and component configurations and assemblies that have been evaluated and appear to be good candidates for field applications. This guide does not constrain field designs or applications of foLs nor should it be regarded as a compendium on the subject.

This document is based on the operating characteristics and installation techniques specific to the Vaive Security Systems, Inc., (VSS) line of FOLSs; it applies to all similar brands of FOLSs.

\subsection{PERFORMANCE REQUIREMENTS}

Performance requirements have not been established at this time for this device. Department of Energy (DOE), Underwriter's Laboratory (UL), or similar regulators or code agencies may have requirements that are applicable to the use of this equipment. It is important to verify local field element requirements and DOE Orders regarding the physical protection of materials,

\footnotetext{
1 Valve Security Systems, P.O. Box 1937, Arvada, CO 80001.
} 
information, and government facilities before using these devices or implementing any designs described in this document or otherwise.

\subsection{SYSTEM AND COMPONENT QUALIFICATIONS}

Several manufacturer's FOLS were evaluated by Sandia National Laboratory (SNL) for function and resistance to high gamma radiation dose rates (see reference 1). The results and conclusions of the SNL evaluation were mixed, with some sensor systems functioning well while others failed to survive the radiation doses. The SNL evaluation did not test defeat scenarios and, at this time, the experience level with using FOLSs in the field as detection elements and tamper seals is low. This being the case, it may be advisable to seek DOE field office concurrance prior to the use of FOLSs for the protection of SNM or other vital/classified interests.

\subsection{COMPONENT DESCRIPTION}

The following list of VSS components is provided to show the different types of FOLSs available for security applications. Other manufactures have similar devices. The existence of this list does not endorse the use of VSS components.

Discussion:

The standard fo cable supplied with vss equipment is $2.2 \mathrm{~mm}$ Mitsubishi Eska Premier type GH4002. This cable has a plastic optic fiber with a polyethylene jacket and is rated for operation from approximately $-55^{\circ} \mathrm{C}$ to $85^{\circ} \mathrm{C}$. It is unaffected by water and resistant to degradation fron sunl ight and most chemicals. The tensile strength is rated at $8 \mathrm{~kg}$, but under certain circumstances it may stretch before breaking. It conforms to UL 1581 ALM WH-1, style \$5310. Other specifications of cable are available for special applications.

In application, the addition of connectors and terminals in FO cable loops reduces the length of useable cable. For the purpose of est imating cable loop length requirements it is generally accepted that a connector is the equivalent of 8 to $15 \mathrm{~m}$ of cable. The $15 \mathrm{~m}$ specification is considered the "safe value" by the manufacturer; the cable-equivalent connector attenuation, especially in short runs of less than 75 or so, may be considerably less.

\subsection{VSS 100}

The VSS 100 operates up to $15 \mathrm{~m}$ of FO cable and is intended for indoor installations. The output can be either 4-20 ma or contact sensing (solid state relay, form $\mathrm{C}, 5-24 \mathrm{vdc}, 30 \mathrm{ma}$ IMax, $0.2 \mathrm{v}$ drop). It has no provisions for tamper protection to prevent accessing the output terminal block; VSS recommends potting the terminal block after connections are made and operation is verified.

Size: $5.3 \mathrm{~cm} \times 5.3 \mathrm{~cm} \times 3.3 \mathrm{~cm}$. Power: 6-24 vdc, 4 ma maximum.

Environmental: $-50^{\circ} \mathrm{C}$ to $70^{\circ} \mathrm{C}, 90 \%$ relative humidity. 


\subsection{VSS 200}

The VSS 200 operates up to $155 \mathrm{~m}$ of FO cable and is intended for indoor or protected exterior applications. The output is form C electro-mechanical relay contacts rated at $100 \mathrm{v}$ maximum and $250 \mathrm{ma}$. It has no provisions for tamper protection to prevent accessing the output terminal block; vSS recommends placing the VSS 200 inside another box equipped with a tamper switch.

Size: $7.6 \mathrm{~cm} \times 6.3 \mathrm{~cm} \times 2.5 \mathrm{~cm}$. Power: 6-24 vdc, 30 ma maximum. Environmental: $-50^{\circ} \mathrm{C}$ to $80^{\circ} \mathrm{C}, 90 \%$ relative humidity.

\subsection{VSS 3008}

The VSS $300 \mathrm{~B}$ is functionally similar to the VSS 200 and, in addition, has programmable address features that allow its use in multi-drop bus schemes. The typical VSS multi-drop implementation is a double distributed network--a personal computer (control and monitor) connects to the primary bus via an RS-232/RS-485 converter that drives up to 32 VSS 3500 NCB network control boxes, each of which connects to up to 60 VSS 300Bs (secondary network). The length of each bus is dependent on the number of devices being used. The maximum lengths are approximately $600 \mathrm{~m}$ and $180 \mathrm{~m}$ for the primary and secondary busses, respectively. The networks are 2 pair cable with one pair used for signal and the other for 12 vdc power. The network cabling is supervised for breaks and loss of communications. Tamper protection is provide as with the VSS 200.

Size: $7.6 \mathrm{~cm} \times 6.3 \mathrm{~cm} \times 4 \mathrm{~cm}$. Power: $12 \mathrm{vdc}, 7$ ma maximum. Environmental: $-50^{\circ} \mathrm{C}$ to $80^{\circ} \mathrm{C}, 90 \%$ relative humidity.

\subsection{VSS 500RF}

The VSS 50ORF is designed to be installed in areas where wiring cannot be easily routed. The 500RF has an internal radio transmitter and is used in conjunction with a VSS 3600 NCB, which is a network control box with a radio receiver. The internal batteries that power the VSS 500RF will last approximately one year if there is little alarm activity. The sensor will transmit alarm, tamper, and low battery; at this time there are no polling or random reporting features. The sensor transmitter is a frequency hopping spread spectrum design operating in the 902-928 $\mathrm{MHz}$ band and requires no $\mathrm{FCC}$ licensing. The useful communications range is dependent on the installation particulars-- $1000 \mathrm{~m}$ may be achievable under line-of-site situations; lesser distances can be expected within and around buildings and other structures. Information on tamper protection was not available from the manufacturer but it is supposed that a tamper switch equipped plastic enclosure will be recommended for tamper protection. 
Size: $11.4 \mathrm{~cm} \times 8.9 \mathrm{~cm} \times 5.6 \mathrm{~cm}$. Power: internal batteries.

Environmental: No specification available on temperature range or $\mathrm{RH}$. The manufacturer describes the device as useful in "a wide range of environmental conditions including outdoor weather."

\subsection{VSS 3500 NCB}

The 3500 NCB is a required item when using $300 \mathrm{~B}$ sensors. It accepts and differentiates the signals from up to 60 of the $300 \mathrm{Bs}$ and sends the information to the monitoring station. Up to 32 NCBs can be placed on a network.

Size: $25.4 \mathrm{~cm} \times 20.3 \mathrm{~cm} \times 10.1 \mathrm{~cm}$. Power: $120 \mathrm{VAC}$

\subsection{VSS 3600 NCB}

The $3600 N C B$ is similar to the $3500 N C B$ with the addition of the receiver necessary for monitoring a $500 \mathrm{RF}$ sensor.

\subsection{VSS 5504RFP, VSS 5508RFP, VSS 5516RFP}

These are portable RF system packages of 4,8 , and 12 sensors intended for quick deployment, convenience, and easy transportability. They use a modified VSS 3600 NCB as the receiver (in a briefcase) and 500RF sensors.

\subsection{VSS $4100 P$, VSS $4200 P$}

VSS $4100 \mathrm{P}$ is an LED display board. The $4200 \mathrm{P}$ is a custom screened panel detailing the floor plan with the LEDs placed in a way that represents the sensor location in relation to the floor plan.

\subsection{VSS $4710 \mathrm{CS}$, VSS $4720 \mathrm{CS}$}

The $4710 \mathrm{CS}$ and $4720 \mathrm{CS}$ are computer systems designed for use with selected VSS FOLSs and contain the CPU, monitor, keyboard and software. The 4720CS is an industrial version with better dust and vibration specifications and is shipped with a backup power supply.

\subsection{PERFORMANCE EXPECTATIONS}

The VSS system and components are used as examples for this performance expectations dialogue. Other sensor systems and components can be expected to have similar specification and attributes. However, testing has shown that 
not all FOLSs perform equally and a manufacturer's specifications and system attributes should be verified prior to specifing a particular FOLS system.

- According to VSS, a component analysis indicates that expected mean-timeto-failure (MTTF) for their devices is between 9 and 14 years at standard conditions. Other manufacturers can be expected to have similar specifications.

- Sensor systems can be expected to perform adequately in areas with low gamma radiation $(<200 \mathrm{MR} / \mathrm{hr}$ ) but the radiation will probably have an effect on the longevity of the device. Quantitative data on MTTF under low level radiation conditions was not available at this writing.

- The standard Fo plastic cable has the following characteristics of interest:

- Cable life expectancy varies with environmental conditions. Data from Mitsubishi indicates that a $20 \mathrm{yr}$ life expectancy is achievable under standard exterior conditions. Two 20 yr baseline specifications cited by Mitsubishi are $30^{\circ} \mathrm{C}$ with $65 \% \mathrm{RH}$ and $25^{\circ} \mathrm{C}$ with $96 \%$ RH. Chemicals, ultraviolet light, and radiation exposure may reduce life expectancy; consult the manufacturer for specific information.

High gamma radiation doses have an attenuating effect on transmittance. This effect is temporary and transmittance will return to near baseline, over a period of time after irradiation ceases if the dose is not above $10^{6}$ RAD. Higher doses cause permanent damage.

- Information on gamma dose rates $>200$ MR but $<10^{4}$ were not available. Degradation and attenuation should be expected to affect operational life and effective transmission distance.

- During periods of exposure to radiation above $200 \mathrm{MR}$, attenuation can be expected and the length of FO loop runs may need to be reduced to provide adequate light strength at the receiver. After exposure ceases and with passing time the transmittance specification should return to near baseline.

- Low gamma dose rates (20-200 MR/hr) have little if any attenuating effect. Long-term low dosage rates may have an accumulative effect and cause an increase in $\mathrm{dB}$ loss per unit length over a period of time. These effects have not been quantified at this time.

- High intensity ambient 1 ight has no effect on black jacketed fiber (CPE, XPE, and PE jacket); gray jacketed fiber (PVC jacket) will admit light and may have noise problems in highly sensitive 
circuits. These problems are unlikely to occur in security applications.

- Splice and connections points are potential problem sites in an FO network. Environmentally sealing these sites is a good practice. The manufacturer should be consulted on the proper sealant for the task.

- Plastic cable will stretch under load. Long term stress on cables may cause a reduction in the diameter of the Fo conductor resulting in a decrease of light transmission through the cable.

- Exposure to extreme temperature may cause Fo conductor to flow, sag, or distort.

- Plastic cables such as Mitsubishi GH4002 (PE jacket) are very rugged and will accept a great deal of abrasive and compressive abuse.

- Plastic FO cables are easily repaired (splice) and terminated; glass F0 cables, generally, are more difficult to repair and terminate.

- Each additional connector installed in a plastic F0 cable loop can be expected to reduce the effective length of the cable by about $15 \mathrm{~m}$. Glass cables are more difficult to splice and the splices can vary greatly in quality; each splice should be checked for transmittance.

- The F0 cable portion of the sensor is unaffected by radio frequency (RF), electrical, or mechanical noise and can operate in noisy environments without additional shielding.

- FO loop sensors with operating features similar to the vSS system are difficult to defeat by substitution of the optic signal.

\subsection{PLANNING AND ENGINEERING INFORMATION}

System planning and design is an engineering task. This section is not intended to influence nor dictate engineering discipline or policy but rather to provide a brief list of items that are germane to fo loop system planning and design.

\subsection{SYSTEM PLANNING}

- Determine system performance and configuration requirements needed to satisfy protection objectives. 
- Read through section 9.2 of this guide and Appendix. Both have information and ideas on using Fo loop sensors.

- Assess each sensor location for potential defeat scenarios. FO loop sensors are reliable alarm sources if the cable must be broken in an attack.

- In some applications the F0 sensor can be used more as a delay or directing mechanism than a detection element by forcing an adversary to use an alternate or more lengthy method of attack.

- Assess environmental variables that may affect operation, maintenance, and longevity.

- Design should comply with safety codes requirements.

- Consult manufacturer's literature for specific operational and design parameters, specifications, and installation recommendations.

- If RF alarm links are appropriate, refer to WHC-SD-SEC-DGS-002, Implementation Guidance for Industrial-Level Security Systems Using Radio Frequency Links, for specific information on implementation.

\subsection{DESIGN AND OPERATIONAL ISSUES}

- Sandia National Laboratory document SAND95-2279, Active Fiber Optic Technologies Used as Tamper-Indicating Devices, has information on several commercial fo loop systems. The document includes the results of some performance and environmental tests, as well as descriptions of the FO loop systems.

- PVC plasticizers of low molecular weight may have a detrimental effect on optic cable jacketing. The use of PVC materials in contact polyethylene jacketed Fo cables should be carefully examined prior to implementation, or altogether avoided.

- Due to the reactive quality of plastics of all types, compatibility with any suspect materials should be evaluated before use.

- In noisy environments the use of RS-485 communications protocol between the sensor alarm terminals and monitoring station may provide more reliable communications.

- If Fo control modules do not have internal and separate tamper protection an enclosure with a tamper switch or other detection element is required to protect the alarm line integrity at the control module terminal block. 
The manufacturer recommends potting the terminal block if the module is not tampered.

- In the case of applications where the protected object is being monitored for small movements, such as a valve handle, Fo cables should have enough tension so that movement of the protected object will cause the cable to separate but not so tight that thermal stress or vibration will disconnect it.

- When a sensor is not in use, the Fo cable should be inserted into the sensor terminals to prevent dust and moisture from accumulating within the terminal connector.

- In cases where the FO loop is well supported, the cable jacket and FO conductor can be "scored" to increase the likelihood that the cable will break cleanly and easily if tampered with.

- The F0 loop can be glued/epoxied/taped to the surface of a protected object or enclosure.

- Fo loop light continuity will be maintained if the ends of a cut cable are butted together, as long as sufficient transmittance still exists. In security applications, the cable could be cut in several places, the cut ends taped together to maintain the light path, and then the cable taped or epoxied to a protected item. An adversary would have a great deal of trouble removing the Fo cable from the protected item without separating the cable at one of the cuts and causing an alarm condition.

- In areas of high humidity it may be necessary to seal both fo terminals and splices and the terminal block of the sensor with a waterproof sealant. The manufacturer should be consulted for compatibility of materials.

- Loss of power to the sensor will cause the alarm state. 
WHC-SD-SEC-DGS-001, Design Guide

May 31,1996

Revision 0

Implementation Guidance for Fiber Optic Loop Sensors

\section{References:}

1. Sandia Report SAND95-2279-UC-515, "Active Fiber Optic Technologies Used As Tamper-Indicating Devices," Horton and Waddoups, November 1995.

2. WHC-SD-SEC-DGS-002, "Implementation Guidance for Industrial-Level Security Systems Using Radio Frequency Alarm Links." 


\section{APPENDIX A}

\section{APPLICATIONS}

Examples of potential applications for FO cable type sensors:

- Gates at remote construction sites and storage areas.

- Doors on warehouses and shipping containers.

- Fuel storage tanks, hoses, and pumps.

- Handles on electrical switches and circuit breakers.

- Rolling stock--wheels, steering wheels, door handles, trailers.

- Portable barricades.

- Valve handles and positioners.

- Manhole covers.

- Hazardous material drums, tank lids, storage racks.

- High cost and attractive items--VCRs, video cameras, computers and computer hardware, tools.

- Gang boxes.

- Use as trip wire.

- Securing penetration such as air ducts with a grid made of fo cable.

- Controlling and documenting critical valve operations or line-ups. 


\title{
APPENDIX B
}

\author{
FIGURES*
}

Figure 1. STEM-TYPE VALVES, SINGLE SENSOR ......... B-2

Figure 2. STEM-TYPE VALVE, MULTIPLE SENSORS .......... B-2

Figure 3. STEM-TYPE VALVES, RF SENSORS ........... B-3

Figure 4 . ROTATING BALL-TYPE VALVE ............ B-3

Figure 5. DRUM MONITOR, SINGLE SENSOR ............. B-4

Figure 6. DRUM MONITOR, RF SENSOR ............. B-4

Figure 7. DRUM MONITOR, MULTIPLE PALLET ............ B-5

Figure 8. HARDWARE MONITOR, INTERNAL APPLICATION $\ldots \ldots$

Figure 9. HARDWARE MONITOR, EXTERNAL APPLICATION ...... B-6

Figure 10. SUPERVISED SENSOR LOOP $\ldots \ldots \ldots \ldots$

Figure 11. EXAMPLE BOLT INSTALLATION DETAIL $\cdots \cdots$

Figure 12. PHOTOGRAPH--EXAMPLE OF BOLT MODIFICATIONS $\ldots \ldots . . .8-8$

Figure 13. PHOTOGRAPH--BOLT, EXAMPLE CABLE ROUTING $1 \ldots \ldots$

Figure 14. PHOTOGRAPH--BOLT, EXAMPLE CABLE ROUTING $2 \ldots . .$.

Figure 15. PHOTOGRAPH--EXAMPLE DRUM RING INSTALLATION $1 \ldots \ldots$

Figure 16. PHOTOGRAPH--EXAMPLE DRUM RING INSTALLATION $2 \ldots . .$. B-10

Figure 17. TYPICAL SENSOR CONNECTION DIAGRAM, EXTERNAL POWER . . B-10

Figure 18. TYPICAL SENSOR CONNECTION DIAGRAM, 4-20 ma LOOP . . . B-11

Figure 19. BLOCK DIAGRAM OF TYPICAL SOLAR POWER APPLICATION . . . B-11

"Figures 1 through 10 and 12 through 18 are being used with the permission of Valve Security Systems, Inc. 


\section{Implementation Guidance for Fiber Optic Loop Sensors}

\section{APPENDIX B}

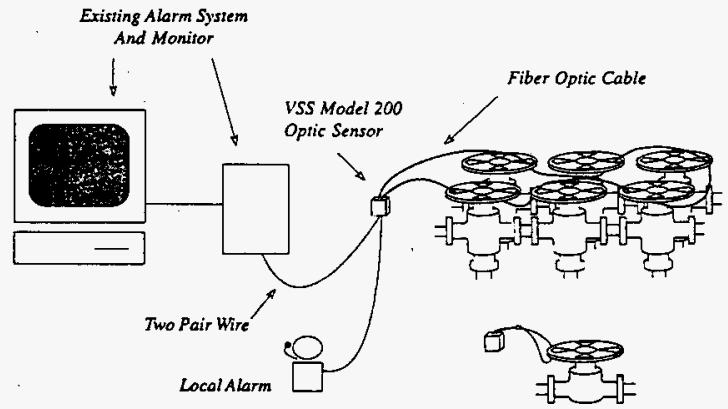

Figure 1. STEM-TYPE VALVES, SINGLE SENSOR

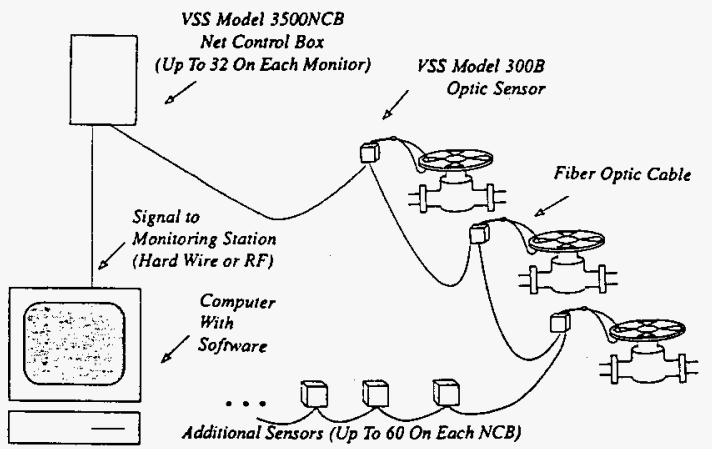

Figure 2. STEM-TYPE VALVE, MULTIPLE SENSORS 


\section{Implementation Guidance for Fiber Optic Loop Sensors}

\section{APPENDIX B}

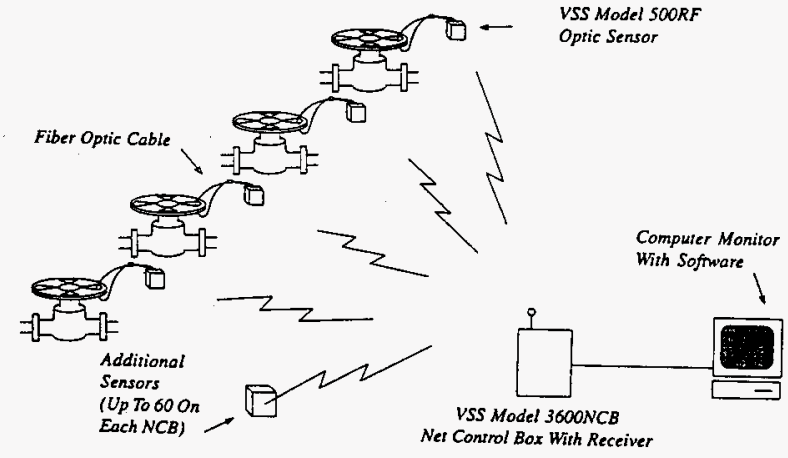

Figure 3. STEM-TYPE VALVES, RF SENSORS

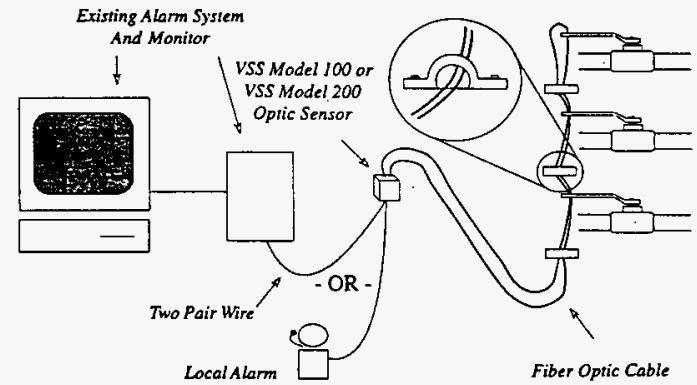

Figure 4. ROTATING BALL-TYPE VALVE 


\section{Implementation Guidance for Fiber Optic Loop Sensors}

\section{APPENDIX B}

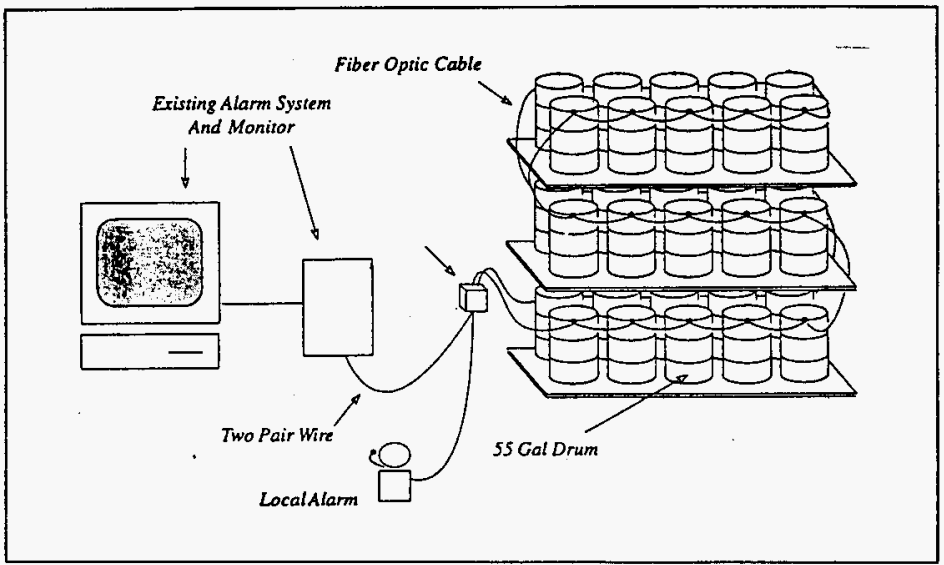

Figure 5. DRUM MONITOR, SINGLE SENSOR

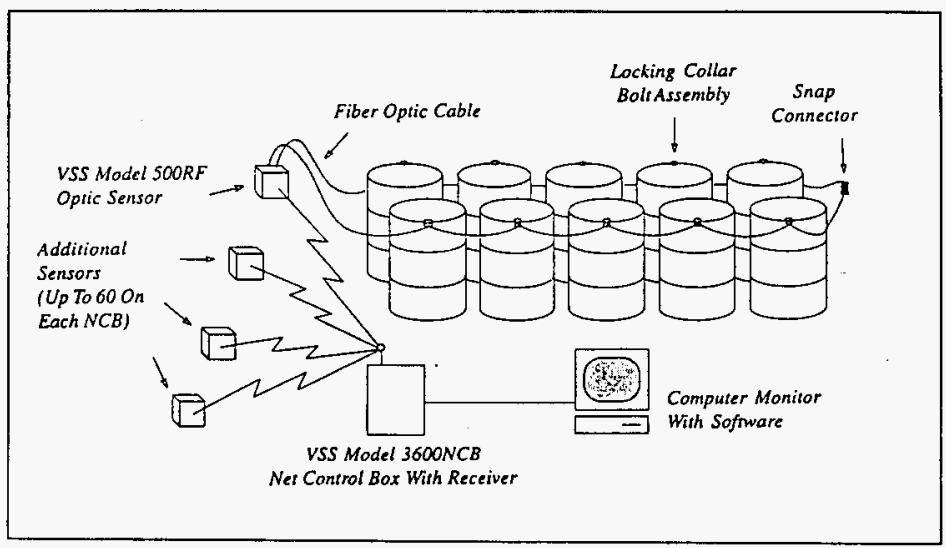

Figure 6. DRUM MONITOR, RF SENSOR 
WHC-SD-SEC-DGS-001, Design Guide

May 31, 1996

Revision 0

Implementation Guidance for Fiber Optic Loop Sensors

\section{APPENDIX B}

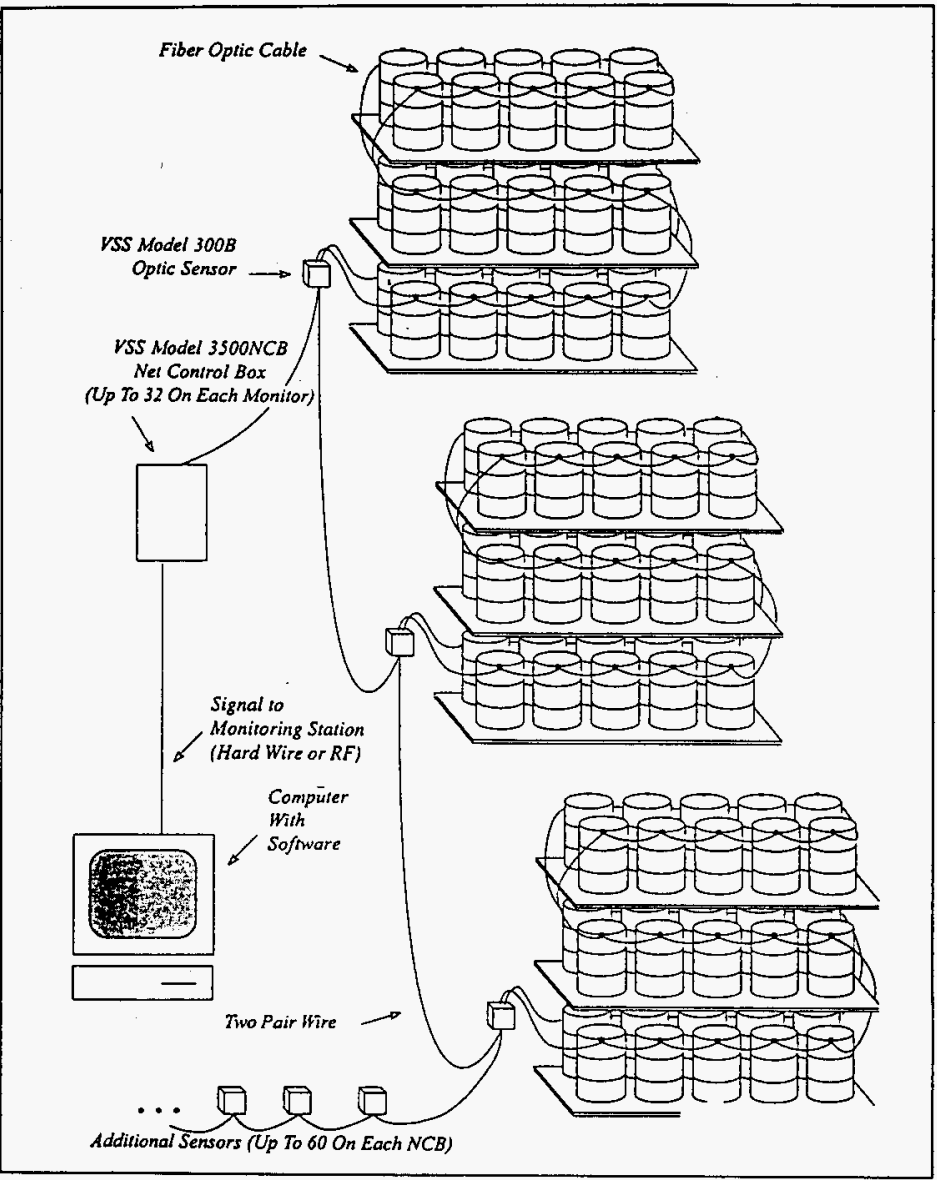

Figure 7. DRUM MONITOR, MULTIPLE PALLET 


\section{Implementation Guidance for Fiber Optic Loop Sensors}

\section{APPENDIX B}

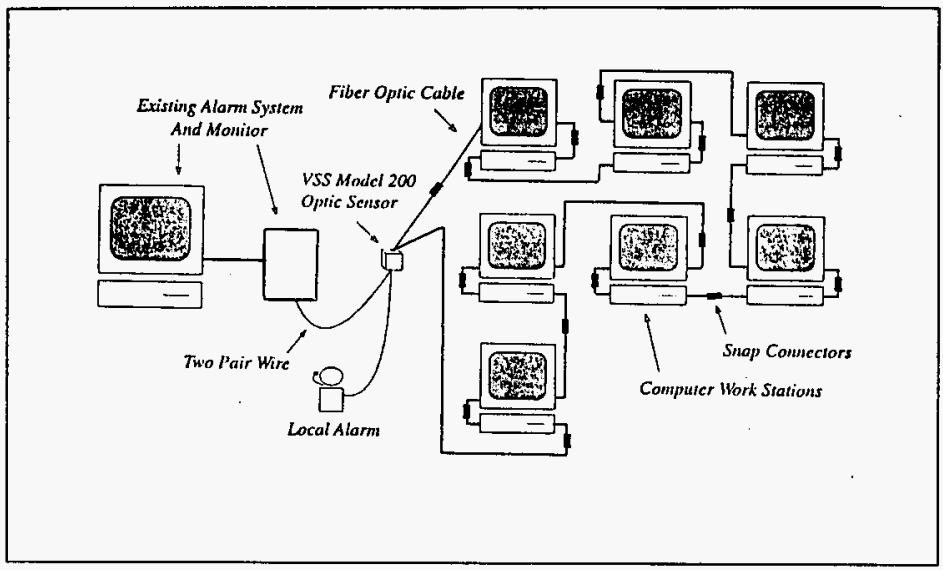

Figure 8. HARDWARE MONITOR, INTERNAL APPLICATION

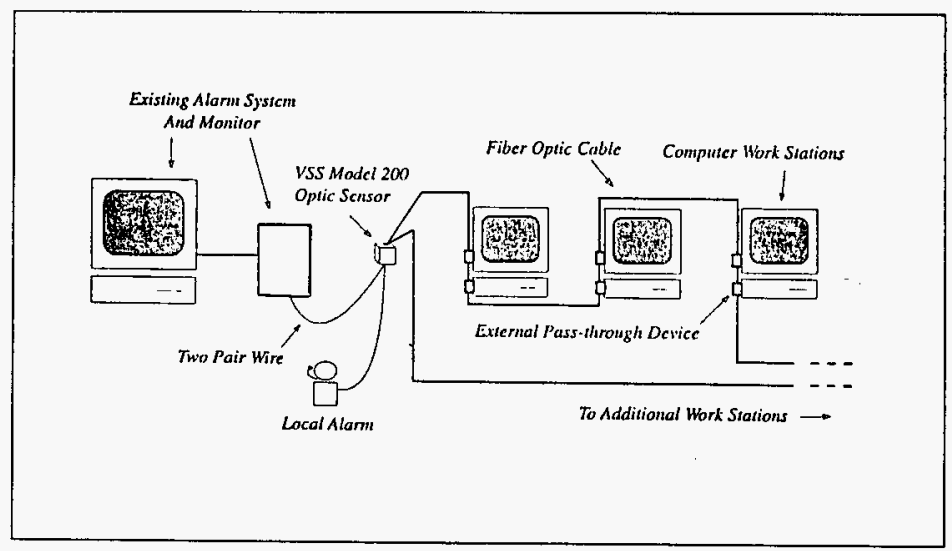

Figure 9. HARDWARE MONITOR, EXTERNAL APPLICATION 
APPENDIX B

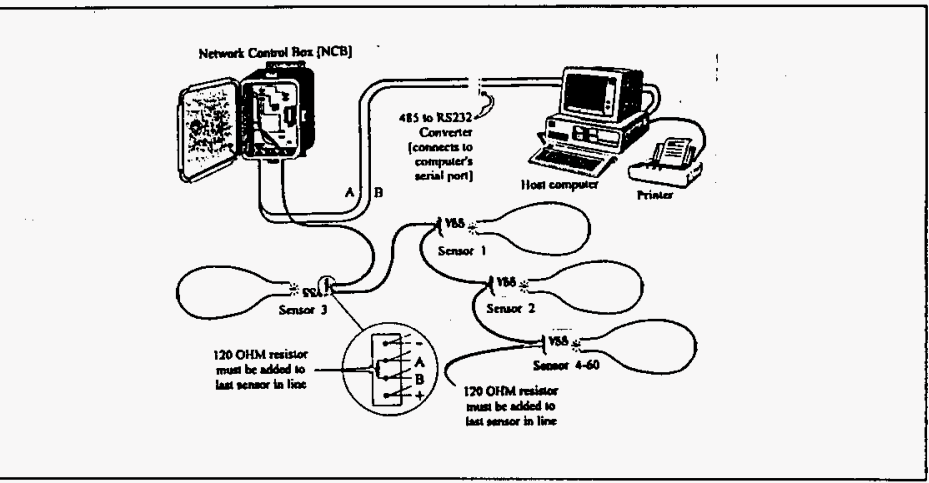

Figure 10. SUPERVISED SENSOR LOOP

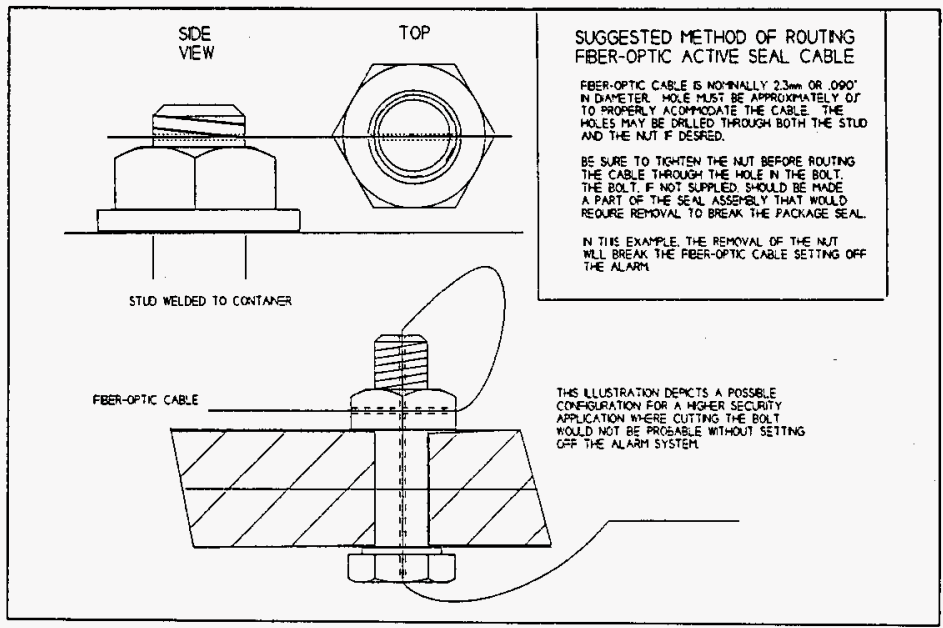

Figure 11. EXAMPLE BOLT INSTALLATION DETAIL 


\section{Implementation Guidance for Fiber Optic Loop Sensors}

\section{APPENDIX B}

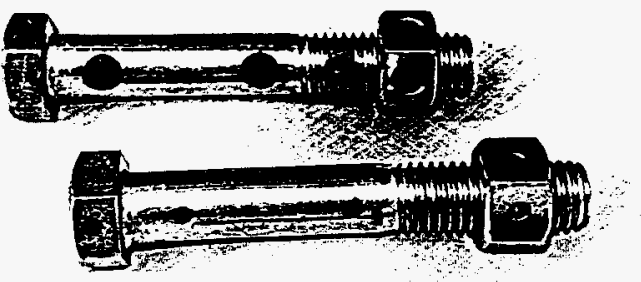

Figure 12. PHOTOGRAPH--EXAMPLE OF BOLT MODIFICATIONS

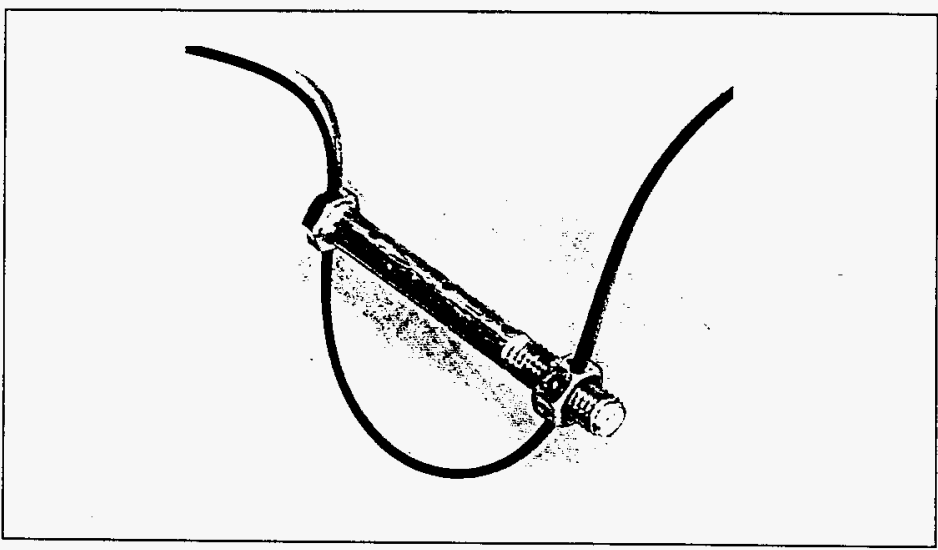

Figure 13. PHOTOGRAPH--BOLT, EXAMPLE CABLE ROUTING 1 
Implementation Guidance for Fiber 0ptic Loop Sensors

\section{APPENDIX B}

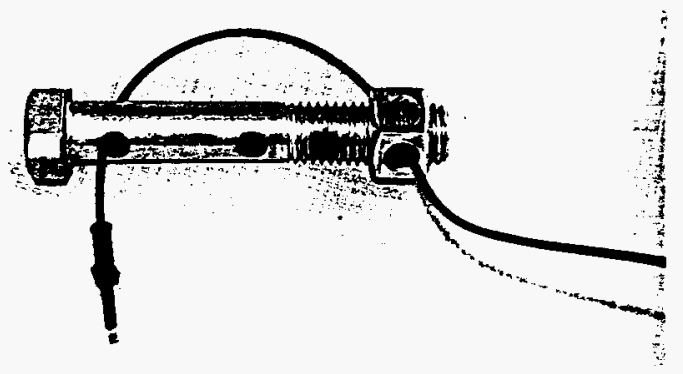

Figure 14. PHOTOGRAPH--BOLT, EXAMPLE CABLE ROUTING 2

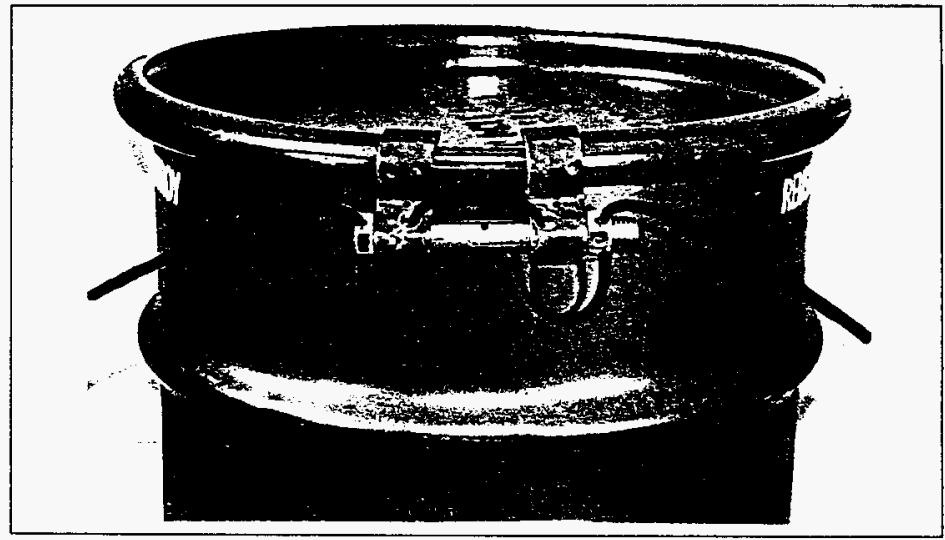

Figure 15. PHOTOGRAPH--EXAMPLE DRUM RING INSTALLATION 1 


\section{Implementation Guidance for Fiber Optic Loop Sensors}

\section{APPENDIX B}

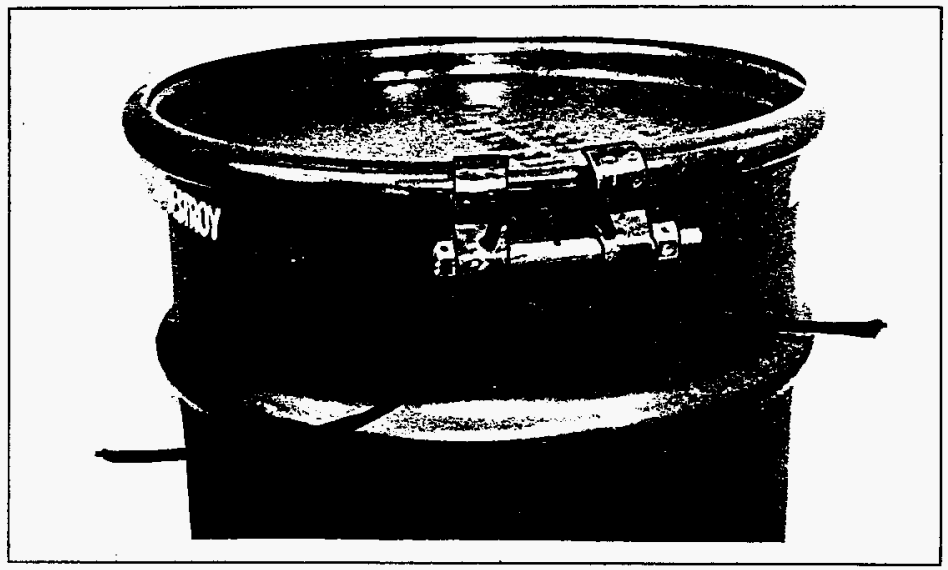

Figure 16. PHOTOGRAPH--EXAMPLE DRUM RING INSTALLATION 2

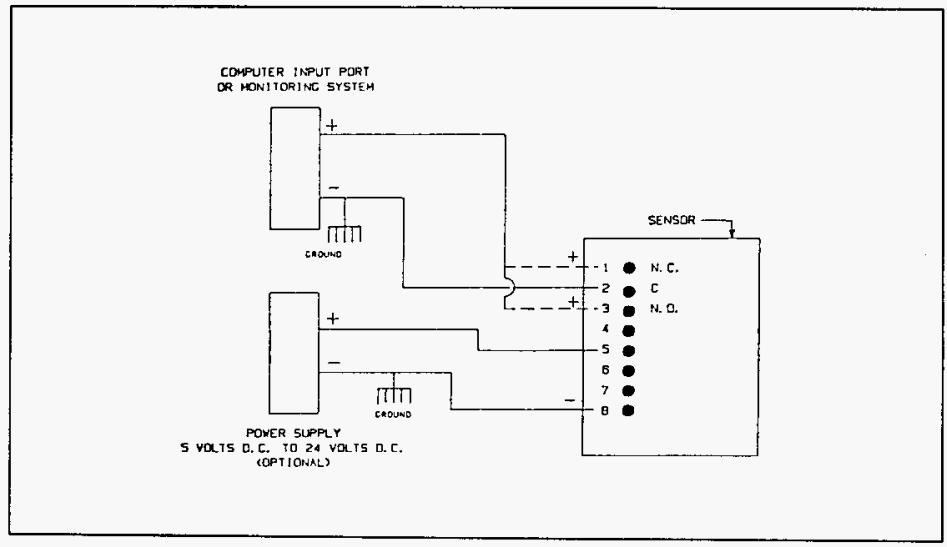

Figure 17. TYPICAL SENSOR CONNECTION DIAGRAM, EXTERNAL POWER 


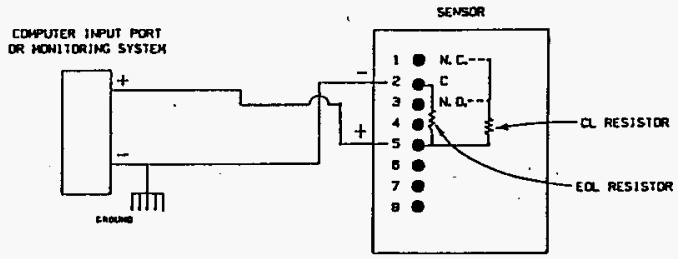

Figure 18. TYPICAL SENSOR CONNECTION DIAGRAM, 4-20 ma LOOP

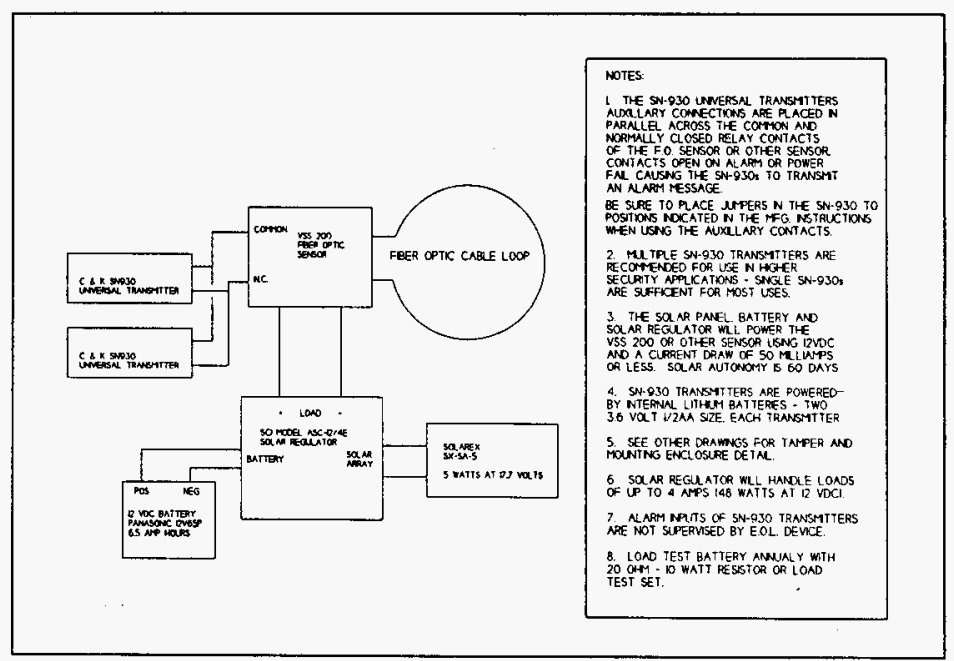

Figure 19. BLOCK DIAGRAM OF TYPICAL SOLAR POWER APPLICATION 